\section{Retention Force and Wear Characteristics of three Attachment Systems after Dislodging Cycles}

\author{
Danny Omar Mendoza Marin ${ }^{1}$, Andressa Rosa Perin Leite ${ }^{1}$, Norberto Martins \\ de Oliveira Junior ${ }^{1}$, André Gustavo Paleari ${ }^{2}$, Ana Carolina Pero', Marco \\ Antonio Compagnoni ${ }^{1}$
}

\author{
'Department of Dental Materials \\ and Prosthodontics, UNESP \\ - Univ Estadual Paulista, \\ Araraquara, SP, Brazil \\ ${ }^{2}$ Department of Restorative Dentistry, \\ UNIFAL - Universidade Federal \\ de Alfenas, Alfenas, MG, Brazil \\ Correspondence: Prof. Ana Carolina \\ Pero, Rua Humaitá, 1680, 14801- \\ 903 Araraquara, SP, Brasil. Tel: \\ +55-16-3301-6411. e-mail: \\ compagno@foar.unesp.br
}

\begin{abstract}
Several attachment systems for mandibular implant-supported overdentures are currently available and studies are required to understand their mechanical properties. The objective of this study was to evaluate the retention force and wear characteristics of three attachment systems in a simulation of the cyclic dislodging of implant-supported overdentures. Thirty samples were fabricated and divided into 3 groups: 1-0-ring; 2-Mini Ball; and 3-Equator. A mechanical fatigue test was applied to the specimens using a servo-hydraulic universal testing machine performing 5500 insertion/removal cycles $(\mathrm{f}=0.8 \mathrm{~Hz})$, immersed in artificial saliva. Retention force values were obtained before and after 1500, 3000, and 5500 cycles using a speed of $1 \mathrm{~mm} / \mathrm{min}$ and a load cell of 1 $\mathrm{kN}$. One specimen from each group was randomly selected and analyzed by scanning electron microscopy. Two-way repeated measures ANOVA and the Bonferroni post hoc test were used for statistical analyses $(\alpha=0.05)$. The 0 -ring system remained stable during all periods tested and exhibited significantly lower retention force values than the Mini Ball and Equator systems. The Mini Ball system exhibited a significant increase in retention force after the mechanical test (baseline $=21.04 \pm 3.29 \mathrm{~N} ; 5500$ cycles $=24.01 \pm 3.30 \mathrm{~N}$ ). The Equator system exhibited a significant decrease in retention force after each period tested, but the values were higher than the other systems. The type of attachment was found to influence retention force in different ways after mechanical tests. The Equator system exhibited the highest retention force values. The Mini Ball and Equator matrices produced deformation and wear on the surfaces without breakage of the polyamide rings.
\end{abstract}

Key Words: denture bases, dental implantation, denture precision attachment, tensile strength.

\section{Introduction}

Although treatment with conventional complete dentures has long been the treatment of choice in the oral rehabilitation of edentulous patients, these individuals have reported several complaints involving difficulties of adaptation, most of which have been associated with mandibular complete dentures and which include lack of retention and stability, chewing difficulties, low selfesteem, and reduced quality of life and satisfaction $(1,2)$.

Today, implant-supported mandibular overdentures retained by two implants associated with a maxillary complete denture have been proposed as the first choice of treatment for edentulous patients (3). This treatment seeks to provide better stability and retention of the mandibular complete denture, thus improving masticatory function of the patient and providing greater satisfaction, better oral health-related quality of life, and comfort (46). Attachments can be used as retention mechanisms and can be classified as splinted systems (bar attachment) or unsplinted systems (o-ring/ball/spherical types, magnets, telescopic crowns or stud attachments) (7).

Several unsplinted attachment systems have been developed in an attempt to improve the retention characteristics and stability of implant-supported overdentures, though they are often produced often without evidence-based features $(8,9)$. The selection of the attachment system has typically been empirical and based largely on the clinician's experience and preference $(8,9)$. This choice may also depend on the subjective retention characteristics of the attachment, not on scientific evidence $(10,11)$. Therefore, knowledge on the different attachment systems and an understanding of their mechanical properties (retention) and load distribution could help clinicians to select the proper attachment for each case (12).

Retention is defined as a quality inherent to a prosthesis that acts to resist the forces of dislodgement along the path of placement (13); it is a major factor in patient satisfaction with removable dentures (14). Therefore, the attachment system must provide a retentive force that is strong enough to prevent overdenture displacement (15), and mechanical and frictional contacts can be the basis of retentive forces (8). In addition, the performance of implant-supported overdentures depends on the retentive capacity of the attachment system employed $(16,17)$. However, the current literature on retentive force and wear of attachment systems is relatively scarce (18). In 
addition, few studies have used the cyclic dislodging test to attempt to simulate a clinical setting $(19,20)$, and no information on retention force or wear is provided by the manufacturers (21).

Two implant-supported overdenture attachment systems (Mini Ball and Equator) have recently been introduced and there is lack information about these attachments in relation to mechanical behavior. Therefore, the aim of this study was to evaluate the retentive behavior and wear characteristics of the Mini Ball and Equator systems during cyclic dislodging in an experimental implant-supported overdenture simulation. The 0-ring attachment was chosen as a control attachment system because ball attachments are considered to be the "most common used attachment" in implant-supported overdenture (22). The null hypothesis was that there would be no differences in retentive force or in wear characteristics among the three types of attachment systems before and after repeated insertion-removal cycles.

\section{Material and Methods}

\section{Attachment Systems and Experimental Models}

The three attachment systems used to retain the implant-supported overdentures evaluated in this study were: 1- the 0-ring attachment (Conexão Prosthesis System, São Paulo, Brazil; Fig. 1A); 2- the Mini Ball attachment (NeoDent, Curitiba, PR, Brazil; Fig. 1B); and 3- the Equator attachment (NeoDent; Fig. 1C). In the case of the Mini Ball attachment, only a white positioner $\left(0^{\circ}\right)$ was used to apply an axial load without angulation. The 0-ring attachment was selected for the control group because is the most common attachment system used in implant-supported mandibular overdentures (22).

\section{Experimental Models}

A modified experimental simulation of an implantsupported overdenture was used $(19,21)$. An aluminum model (lower member) and an acrylic model (upper member) that were $20 \mathrm{~mm}$ in height and $40 \mathrm{~mm}$ in diameter were
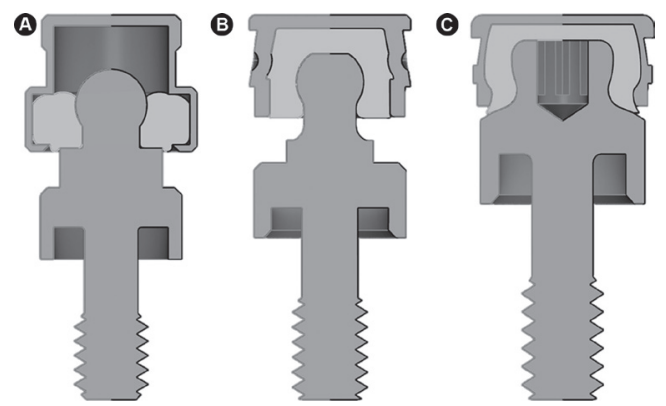

Figure 1. Schematic representation of the attachment systems. A: O-ring; B: Mini Ball; C: Equator. fabricated for the purposes of this study (Fig. 2). The aluminum master cast was formed by two parallel implant analogues (TitamaxTi, RN, $\varnothing 4.1 \times 10$ mm, NeoDent, Curitiba, $P R$, Brazil) with an inter-implant distance of $22 \mathrm{~mm}$, because this distance is similar to the space between two natural canines (21). These values were used for all of the samples, regardless of the attachment system tested. All attachment retainers (patrices) of each system were screwed into this base using a ratchet and torque control device (NeoDent) as per the manufacturer's instructions (0-ring: $20 \mathrm{Ncm}$; Mini Ball: $32 \mathrm{Ncm}$; Equator: $32 \mathrm{Ncm}$ ).

The acrylic master cast was fabricated using a Teflon matrix and respecting the dimensions of the aluminum master cast. It was filled with auto-polymerizing polymethylmethacrylate (PMMA) resin (Clássico Artigos Odontológicos, São Paulo, SP, Brazil) to obtain two precision titanium housing spaces for the dedicated attachment system. The attachment titanium housings (matrices) of each system were attached to the retainers and inserted into the acrylic master cast as per the manufacturer's instructions and using the same PMMA resin. Caution was taken to avoid excess material being placed into the titanium housing spaces, and all models underwent for a quality control check before testing (17).

\section{Feasibility and Reliability of Data Collection and Sample Size}

Before the experimental testing, 10 initial retention values were obtained in Newtons $(\mathrm{N})$ for each attachment system $(n=10)$ using an inter-implant distance of $22 \mathrm{~mm}$; these values were obtained on two separate occasions with an interval of seven days. The intra-examiner reproducibility of the quantitative data (retention value) was analyzed using the intraclass correlation coefficient (ICC). According to the values obtained, all of the retention values exhibited good or excellent agreement in all of the

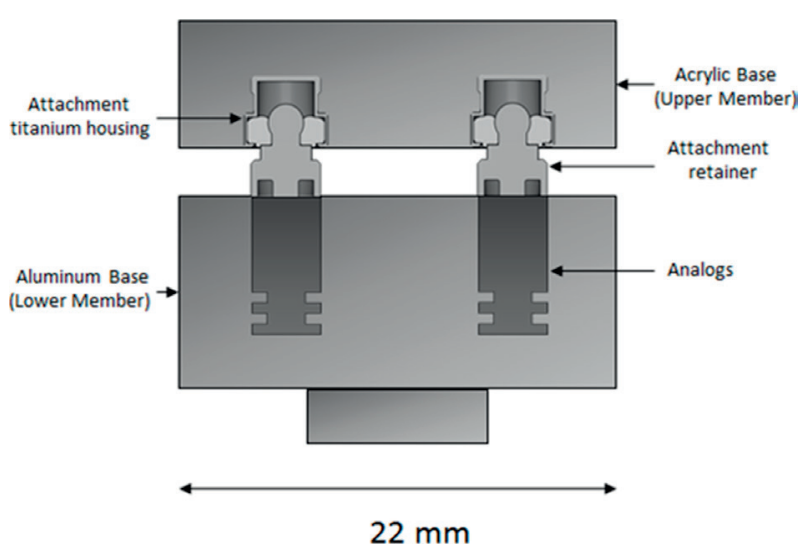

Figure 2. Test model configuration. 
test groups ( 0 -ring $I C C=0.92$; Mini Ball ICC $=0.89$; Equator $I C C=0.96)$. These results show that the data collection procedures were preceded by the appropriate calibration, a step which contributes to the highly reliability of the measurements. In addition, sample size was calculated with an initial sample of 30 specimens undergoing the proposed protocol. Thus, the sample size was determined to be 10 specimens per group, an amount which allowed for the detection of a minimal significant difference of 28 $N$ with $\alpha=.05$ and $\beta=.20$.

\section{Retention Measurements}

The specimens were submitted to fatigue and tensile strength tests using a servo-hydraulic universal testing machine (MTS 810 Material Testing System, MTS System Corp., Eden Prairie, MN, USA). Two metallic devices were fabricated (15 mm in height and $60 \mathrm{~mm}$ in diameter) to place and fix the specimens in the universal testing machine by means of three screws located around the device. Component insertion and removal movements were performed along the long axis of the implant.

\section{Fatigue Test}

All specimens were immersed in artificial saliva (1.5 $\mathrm{mmol} / \mathrm{L} \mathrm{Ca}, 3.0 \mathrm{mmol} / \mathrm{L} \mathrm{P}, 20.0 \mathrm{mmol} / \mathrm{L} \mathrm{NaHCO}_{3}, \mathrm{pH} 7.0$ ) to simulate a wet environment at room temperature. The specimens were artificially aged using a function generator (MTS System Corp.), and a mechanical fatigue test with 5500 insertion-removal cycles was applied along the long axis of the implant $(f=0.8 \mathrm{~Hz})$. According to other studies $(19,21)$, 5500 cycles of mechanical fatigue testing correspond to 5 years of prosthesis usage, based upon patients' average use of 3 insertions-removal cycles per day.

\section{Tensile Testing}

Tensile strength was tested using the TestWorks for TestStar software (MTS System Corp.) and the MTS 810 Material Testing System (MTS System Corp.) with a load cell of $1 \mathrm{kN}$ and speed of $1 \mathrm{~mm} / \mathrm{min}^{-1}$, to measure retention force. During the dynamic fatigue test, four values were taken to observe the long-term behavior of the retention force of the attachments systems: at baseline and at 1500, 3000, and 5500 cycles. After each interval, all specimens were fixed in the two metallic devices in the universal testing machine and the maximum retention force values were an average of five measurements taken at each interval.

\section{Scanning Electron Microscopy (SEM)}

One specimen from each group was randomly selected and analyzed by scanning electron microscopy. A SM-300 scanning electron microscope (Topcon Corporation, Japan) was used for the qualitative evaluation of the surface. SEM images were obtained at baseline and after 5500 cycles, and were analyzed to determine possible wear patterns during the mechanical tests on the patrices and matrices. SEM was used to identify any changes that may have occurred to the structure of attachment systems during the mechanical tests.

\section{Statistical Analysis}

All of the data collected was first analyzed using the Shapiro-Wilk test for normal distribution ( $p>0.05$ ). To evaluate and compare the effects of the three attachment systems and the 4 cycle periods in terms of their influence on retention force, the two-way repeated-measures ANOVA (mixed design) parametric test was used. In cases with significant differences, multiple comparisons were performed using the Bonferroni test. All of the data was analyzed using the PASW Statistics software, version 19 (SPSS Inc., Chicago, Illinois, USA), with the significance level set at $\alpha=0.05$. A qualitative approach was used to evaluate the SEM images.

\section{Results}

According to the results, there was a significant difference $(p<0.001$; Power $(\pi)=1.000)$ in the mean retention force values exhibited by the different attachment systems. The 0 -ring system $(\mu=7.16 \pm 064 \mathrm{~N})$ had the lowest values, followed by the Mini Ball system ( $\mu=22.32$ $\pm 0.64 \mathrm{~N})$, and the Equator system $(\mu=44.71 \pm 0.64 \mathrm{~N})$, which exhibited the highest values. When the retention force was evaluated in relation to the number of cycles, significant differences were found between the 4 cycles periods $(p<0.001$; power $(\pi)=1.000)$. The retention force was higher at baseline $(\mu=26.80 \pm 0.45 \mathrm{~N})$ and was found to decrease as the number of cycles increased $(1500$ cycles: $\mu=25.60 \pm 0.47 \mathrm{~N} ; 3000$ cycles: $\mu=2455 \pm 0.52$ $\mathrm{N}$ and 5500 cycles: $\mu=21.97 \pm 0.45 \mathrm{~N}$ ), irrespective of the attachment system.

Finally, the effect of the number of cycles (baseline, 1500,3000 and 5500 cycles) on retention force depended of the type of attachment system used (0-ring, Mini Ball, or Equator), As shown in Table 1, the three attachment systems differed during all of the cycle periods tested. The 0-ring system remained stable during all cycle periods tested while the Mini Ball system exhibited an increase in retention force after the mechanical fatigue test. The highest values were obtained after 5500 cycles ( $\mu=24.01$ $\pm 3.30 \mathrm{~N}$ ), and the other periods presented intermediate values. However, the Equator system exhibited a decrease in retention force after each period tested. The lowest values were found after 5500 cycles $(\mu=34.67 \pm 2.22 \mathrm{~N})$.

The SEM revealed significant changes in the matrices 
of the three attachment systems. As seen in Figure 3, the details of the 0-ring, Mini Ball, and Equator matrices,

Table 1. Retention force (mean $\pm \mathrm{SD}$, in $\mathrm{N}$ ) according to the three attachment systems and number of cycles.

\begin{tabular}{lcccc}
\hline \multirow{2}{*}{ Group } & \multicolumn{4}{c}{ Retention Force in Newton (N) } \\
\cline { 2 - 5 } & 0 (baseline) & 1500 cycles & 3000 cycles & 5500 cycles \\
\hline O-ring & $7.56 \pm 0.59 \mathrm{Aa}$ & $7.01 \pm 0.64 \mathrm{Aa}$ & $6.85 \pm 1.17 \mathrm{Aa}$ & $7.21 \pm 1.53 \mathrm{Aa}$ \\
Mini Ball & $21.04 \pm 3.29 \mathrm{Ab}$ & $21.94 \pm 3.26 \mathrm{ABb}$ & $22.30 \pm 3.64 \mathrm{ABb}$ & $24.01 \pm 3.30 \mathrm{Bb}$ \\
Equator & $51.81 \pm 2.64 \mathrm{Ac}$ & $47.86 \pm 2.99 \mathrm{Bc}$ & $44.51 \pm 3.14 \mathrm{Cc}$ & $34.67 \pm 2.22 \mathrm{Dc}$ \\
\hline
\end{tabular}

Horizontally, different uppercase letters indicate significant differences in the horizontal direction. Vertically, different lowercase letters indicate significant differences in the vertical direction (Bonferroni test, $\mathrm{p}<0.05$ ). respectively, before and after 5500 cycles, are showed. The 0 -ring matrix was found to have a smooth surface, and the original features of the specimen were found to be preserved without damage to or disruption of the nitrile ring. The Mini Ball and Equator matrices were found to have deformation and wear on the internal and external surfaces without breakage of the polyamide rings, a result which can be seen more clearly in the Equator system. Changes to the polyamide rings were associated with simulated insertion and removal movements.
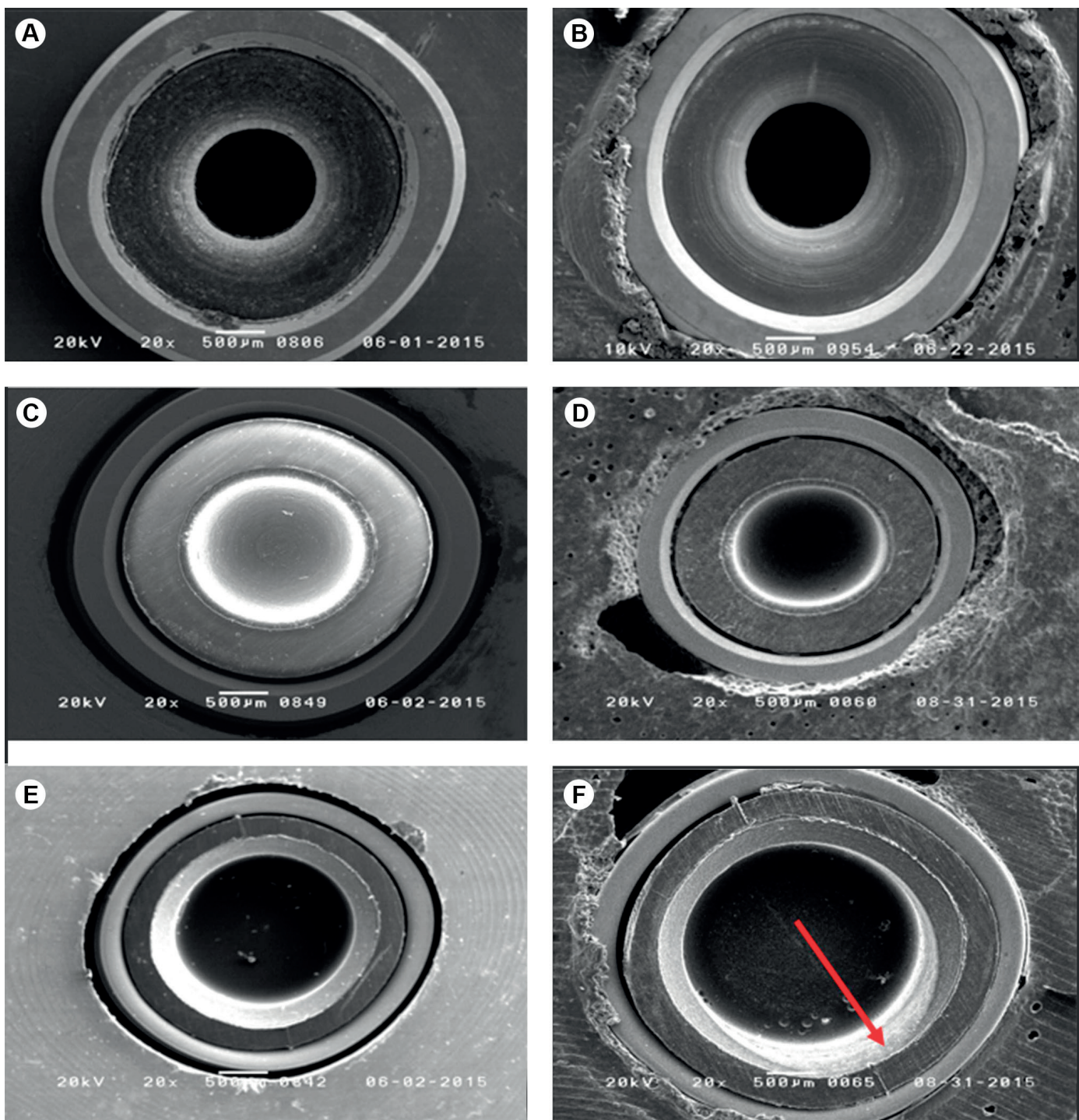

Figure 3. SEM images of the 0-ring matrix (A, B); Mini Ball (C, D); and Equator (E, F) before and after fatigue test (5500 cycles). The 0-ring matrix was found to have a smooth surface and preservation without damage to or disruption of the nitrile ring. The Mini Ball and Equator matrices were found to have deformation and wear on the internal and external surfaces without breakage of the polyamide rings. Arrow shows deformation of and wear on the internal and external surfaces. 


\section{Discussion}

The predictability and maintenance needs of an implantsupport overdentures are associated with the long-term retention ability of the attachment system (16). In the present study, a servo-hydraulic universal testing machine and a scanning electron microscopy were used to evaluate the retention force and wear characteristics before and after 5500 cycles of three different attachment systems. The null hypothesis that there would be no differences in retentive force or wear characteristics among the three types of attachment systems was rejected. A significant difference was observed when the attachment systems were compared to each other, and this difference reflects the maintenance of, increase in, or decrease in retention force, depending on the type of attachment system in question.

The simulated insertion-removal cycles did not influence the retention force of the 0-ring system. This system exhibited the lowest retention values during all of the cycle periods tested and differed significantly from the other attachment systems. These finding are in accordance with another study (19), in which the 0-ring system also remained stable during all of the cycle periods tested. This stability could be explained by the elasticity of the ring and design of the patrix, as well as by the frictional resistance between them (19). In addition, SEM revealed a small amount of wear, a smooth surface, and the preservation of the original features of the nitrile ring after 5500 cycles, findings which would explain the consistent retention values.

The improvement in retentive force measurements observed in the case of the Mini Ball system could be explained by the possible association between deformation and the increased hardness of the polyamide rings. This association would result in a decrease in the diameter of the internal retentive ring and, as a consequence, in an increase in retention force (19). In addition, the abutment design (small diameter ball) could have influenced the deformation of the polyamide ring, thus improving the surface contact between components. This increase was minimal (3N-14\%); it became significant only after 5500 cycles relative to baseline and was consistent in the other periods tested. The SEM analysis of the Mini Ball system revealed some microscopic changes, which are signs of deformation, wear, and increased roughness of the matrix. These changes are slighter than those found in the Equator system, but were enough to increase the retention force of the attachment.

The Equator system exhibited a significant and progressive loss in retention force after each cycle period tested. Retention force experienced a loss of approximately of $33.08 \%$ after 5500 insertion-removal cycles relative to baseline. Other researchers $(15,23,24)$ found loss in retention force in studies of other attachment systems based on cylindrical patrices and polymeric matrices using insertion-removal cycles. The loss of retention found in the Equator system could be explained by greater deformation of and wear on the internal and external surfaces without breakage of the polyamide ring, as confirmed by SEM. It could be hypothesized that the design of the Equator system contributed to greater deformation and wear, since the friction between the components was higher than that of the Mini Ball system and led to a decrease in retention values. These outcomes are in accordance with those of other studies $(7,16)$, which have associated a loss of retention of attachment systems to deformation and wear of the polymeric ring, as confirmed by SEM (16). Nevertheless, despite the loss of retention over time, the Equator system exhibited the highest values in all of the cycle period tested when compared to the other attachments, a difference which could be explained by the characteristics of the polyamide. This choice would be an advantage in clinical practice in that it would decrease follow-up visits, component replacements, and maintenance costs for patients.

The material, design, and dimensions of the attachment system can influence retention force (9). 0-rings are made of rubber nitryl, and their features include elastic properties, wear resistance, compressive strength, and resistance against steel (19). The retentive rings used in the Mini Ball and Equator systems are made of a polyamide and possesses smooth surface finish, chemical resistance, impact strength, low density, light weight, burst strength, and abrasion and scratch resistance. In addition, they offer flexibility, resistance to aging, permeability, and temperature, as well as dimensional stability; they are also more rigid than rubber nitryl. These characteristics could explain the high retention values of these attachments when compared to those of the 0-ring attachment. Also, according to the manufacturer, the Equator attachment presents a violet female component with higher retentive properties. In this study, the pink female component for regular retention was used. A future study should be carried out to compare the performance of the violet female component.

As our outcomes show, retention force varies between the attachments. When the 0 -ring and Mini ball systems are compared, both can be classified as a ball/spherical attachment, but they exhibit different characteristics. Botega et al. (19) (2004) concluded that ball attachments with larger patrices have more retention force values than similar attachments of smaller dimensions using same matrix material due to an increase in frictional contact between the patrices and matrices. Our study found that the material used in the matrix in ball/spherical attachments has more influence on retention force, regardless of the patrix 
dimensions. However, when attachments with different dimensions and the same matrix material are compared, the attachment dimensions are found to influence the retention force, as shown when the Mini Ball and Equator systems were compared.

A total of 5500 insertion-removal cycles of fatigue testing in a vertical direction were applied. Several studies $(7,17,21,25)$ have employed different quantities of cycles to simulate clinical wear of the attachment systems, but the literature currently lacks a consensus regarding the number of cycles necessary to simulate an ideal clinical wear situation in in-vitro studies evaluating retention force over time. In the current study, 5500 cycles were used to simulate an in-vivo function of 5 years, because this amount corresponds to clinical use of an implant-supported overdenture over five years with three insertion-removal cycles per day, a period which is considered sufficient for prosthesis replacement (21).

In addition, according to Bayer et al. (26), the use of a lubricant is necessary to simulate clinical conditions during wear simulation testing because it affects retention force. In this study, artificial saliva was used during all fatigue and tensile tests. Some studies $(7,16,26)$ used demineralized water, a physiological sodium chloride solution $(\mathrm{NaCl})$, or different composition of artificial saliva as a lubricant, but the use of any lubricant different from saliva would not provide realistic results regarding the clinical behavior of an attachment system (26). The rheological behavior of saliva is determined by its mucin components, which reduce surface tension to moisten the intraoral surface, and this effect can be simulated by saliva substitutes (26). However, there is currently no consensus regarding the ideal lubricant for in-vitro tests, and more studies comparing all available lubricants are necessary to determine which saliva substitutes should be used (26).

The three systems exhibited different behaviors in terms of their effects on retention force values, but no retention value was lower than $7 \mathrm{~N}$. The literature reports that retention forces from $5 \mathrm{~N}$ to $7 \mathrm{~N}$ are necessary for an attachment system to keep an overdenture in position during use (21). Therefore, regardless of the type of attachment system used, all of the retention forces found herein would still be acceptable, even after 5500 cycles.

According to the literature, studies have not established a consensus regarding how much is considered a sufficient retention value for clinical situation. During the selection of the attachments systems factors as available bone, patient prosthetic expectation and economical status must be considered (12). In cases with extremely resorbed ridges an attachment systems with high degree of retention should be recommended $(12,27)$. Attachment systems with low retention, should be used in case of bruxism (27) or immediate load because less excessive force will be delivered to the implants, increasing the survival rate of implants and the long-term use of the prosthesis. In addition, patient with dexterity problems could be benefit with attachment with low retention (27) helping removal and hygiene of the prosthesis.

One limitation of this study was the use of a monodirectional vertical force, which not entirely represent a clinical situation. Horizontal and lateral forces will act on the attachment system during functional movements, but these forces are very difficult to simulate in an in-vitro study . In addition, clinical studies must be conducted to validate the in vitro outcomes of each attachment system tested in this study. Clinical studies are also suggested to measure patient-centered outcomes, such as patient satisfaction, oral health-related quality of life, as the need for maintenance, and possible disadvantages of or complications associated with the use of these attachment systems.

Within the limitations of this in vitro study, that the following conclusions can be made: attachment systems exhibit different mechanical behavior depending on the type of attachment system; retention force is influenced by the design of the attachment system, by the matrix material and by patrix dimensions; and all of the attachment systems evaluated presented adequate retention values for clinical usage; and the simulation of insertion-removal cycles results in a slight wear on the matrix of the 0-ring system, with consistent retention values over time. The Equator system was found to exhibit the highest retention values during all of the periods tested. However, enough deformation and wear were observed on the polyamide components of Mini Ball and Equator systems to significantly increase the retention force of the Mini Ball system and to decrease the retention forces of the Equator system.

\section{Resumo}

Vários sistemas de encaixe para sobredentaduras mandibulares implantossuportadas estão atualmente disponiveis e estudos são necessários para entender as suas propriedades mecânicas. 0 objetivo deste estudo foi avaliar a força de retenção e as caracteristicas de desgaste de três sistemas de encaixe por meio de uma simulação de deslocamento cíclico de sobredentaduras implantossuportadas. Trinta amostras foram fabricadas e divididas em 3 grupos: 1-0-ring; 2-Mini Ball; e 3-Equador. Um teste de fadiga mecânica foi aplicado aos espécimes utilizando uma máquina de teste universal servo-hidráulica com 5500 ciclos de inserção/remoção ( $f=0,8 \mathrm{~Hz}$ ), imersos em saliva artificial. Os valores da força de retenção foram obtidos antes e após 1500, 3000 e 5500 ciclos utilizando uma velocidade de $1 \mathrm{~mm} / \mathrm{min}$ e uma célula de carga de $1 \mathrm{kN}$. Um espécime de cada grupo foi selecionado aleatoriamente e analisado por microscopia eletrônica de varredura. 0 teste de Análise de Variância a dois fatores para medidas repetidas e o teste de comparações múltiplas de Bonferroni foram utilizados para análises estatísticas $(\alpha=0,05)$. 0 sistema de 0-ring permaneceu estável durante todos os períodos testados e apresentou valores de força de retenção significativamente menores do que os sistemas Mini Ball e Equator. 0 sistema Mini Ball apresentou 
um aumento significativo na força de retenção após o teste mecânico (controle $=21,04 \pm 3,29 \mathrm{~N} ; 5500$ ciclos $=24,01 \pm 3,30 \mathrm{~N}$ ). 0 sistema Equator apresentou uma diminuição significativa na força de retenção após cada periodo testado, mas os valores eram maiores do que os outros sistemas. 0 tipo de sistema de encaixe influenciou na força de retenção de diferentes maneiras após testes mecânicos. 0 sistema do Equador exibiu os maiores valores de força de retenção. As matrizes dos sistemas Mini Ball e Equator produziram deformação e desgaste nas superficies sem ruptura dos anéis de poliamida.

\section{Acknowledgements}

The authors gratefully acknowledge the support provided by NeoDent and Conexão Sistemas de Prótese for donation of prosthetic components. The authors declare no potential conflicts of interest with respect to the authorship and/or publication of this article.

\section{References}

1. Emami E, Heydecke G, Rompre PH, de Grandmont P, Feine JS. Impact of implant support for mandibular dentures on satisfaction, oral and general health-related quality of life: a meta-analysis of randomizedcontrolled trials. Clin Oral Implants Res 2009;20:533-544.

2. Marin DOM, Leite ARP, Paleari AG, Rodriguez LS, Oliveira Junior NMd, Pero AC, et al. Effect of a denture adhesive on the satisfaction and kinesiographic parameters of complete denture wearers: a cross-over randomized clinical trial. Brazilian Dental Journal 2014;25:391-398.

3. Feine JS, Carlsson GE, Awad MA, Chehade A, Duncan WJ, Gizani S, et al. The McGill consensus statement on overdentures. Mandibular twoimplant overdentures as first choice standard of care for edentulous patients. Int J Oral Maxillofac Implants 2002;17:601-602.

4. Visser A, Raghoebar GM, Meijer HJ, Batenburg RH, Vissink A. Mandibular overdentures supported by two or four endosseous implants. A 5-year prospective study. Clin Oral Implants Res 2005;16:19-25.

5. Muller F, Duvernay E, Loup A, Vazquez L, Herrmann FR, Schimmel M. Implant-supported mandibular overdentures in very old adults: a randomized controlled trial. J Dent Res 2013;92:154-160.

6. Melo LAd, Souza MBCd, Barbosa GAS, Carreiro AdFP. Peri-implant bone loss of external hexagon and morse taper in patients wearing immediately loaded overdentures. Braz Dent J 2017;28:694-698.

7. Kobayashi M, Srinivasan M, Ammann P, Perriard J, Ohkubo C, Muller $F$, et al. Effects of in vitro cyclic dislodging on retentive force and removal torque of three overdenture attachment systems. Clin Oral Implants Res 2014; 25:426-434.

8. Daou EE. Biomaterial aspects: A key factor in the longevity of implant overdenture attachment systems. J Int Soc Prev Community Dent 2015;5:255-262.

9. Alsabeeha NH, Payne AG, Swain MV. Attachment systems for mandibular two-implant overdentures: a review of in vitro investigations on retention and wear features. Int J Prosthodont 2009;22:429-440.

10. Lee DJ. Performance of attachments used in implant-supported overdentures: review of trends in the literature. J Periodontal Implant Sci 2013:43:12-17.
11. Kim HY, Lee JY, Shin SW, Bryant SR. Attachment systems for mandibular implant overdentures: a systematic review. J Adv Prosthodont 2012;4:197-203.

12. Prasad DK, Prasad DA, Buch M. Selection of attachment systems in fabricating an implant supported overdenture. J Dent Implant 2014;4:176-181.

13. The glossary of prosthodontics terms. J Prosthet Dent 2005;94:69

14. Cune $M$, van Kampen $F$, van der Bilt A, Bosman F. Patient satisfaction and preference with magnet, bar-clip, and ball-socket retained mandibular implant overdentures: a cross-over clinical trial. Int $J$ Prosthodont 2005;18:99-105.

15. Setz I, Lee SH, Engel E. Retention of prefabricated attachments for implant stabilized overdentures in the edentulous mandible: an in vitro study. J Prosthet Dent 1998;80:323-329.

16. Rutkunas V, Mizutani $\mathrm{H}$, Takahashi $\mathrm{H}$, Iwasaki N. Wear simulation effects on overdenture stud attachments. Dent Mater J 2011;30:845853.

17. Srinivasan $M$, Schimmel $M$, Badoud $I$, Ammann $P$, Herrmann $F R$, Muller F. Influence of implant angulation and cyclic dislodging on the retentive force of two different overdenture attachments - an in vitro study. Clin Oral Implants Res 2016;27:604-611.

18. Alsabeeha N, Atieh M, Payne AG. Loading protocols for mandibular implant overdentures: a systematic review with meta-analysis. Clin Implant Dent Relat Res 2010;12:28-38.

19. Botega DM, Mesquita MF, Henriques GE, Vaz LG. Retention force and fatigue strength of overdenture attachment systems. J Oral Rehabil 2004;31:884-889.

20. da Fontoura Frasca LC, Castro Mattia PR, Botega DM, Rivaldo EG. Evaluation of retention forces and resistance to fatigue of attachment systems for overdentures: plastic and metal components. Implant Dent 2014;23:451-455.

21. Pigozzo MN, Mesquita MF, Henriques GE, Vaz LG. The service life of implant-retained overdenture attachment systems. J Prosthet Dent 2009;102:74-80.

22. Naert I, Alsaadi G, Quirynen M. Prosthetic aspects and patient satisfaction with two-implant-retained mandibular overdentures: a 10-year randomized clinical study. Int J Prosthodont 2004;17:401-410.

23. Chung $\mathrm{KH}$, Chung $\mathrm{CY}$, Cagna DR, Cronin RJ, Jr. Retention characteristics of attachment systems for implant overdentures. J Prosthodont 2004;13:221-226.

24. Evtimovska $E_{1}$ Masri $R$, Driscoll $C F$, Romberg E. The change in retentive values of locator attachments and hader clips over time. J Prosthodont 2009;18:479-483.

25. Turk PE, Geckili 0 , Turk $Y$, Gunay V, Bilgin T. In vitro comparison of the retentive properties of ball and locator attachments for implant overdentures. Int J Oral Maxillofac Implants 2014;29:1106-1113.

26. Bayer S, Keilig L, Kraus D, Gruner M, Stark H, Mues S, et al. Influence of the lubricant and the alloy on the wear behaviour of attachments. Gerodontology 2011;28: 221-226.

27. Trakas T, Michalakis K, Kang K, Hirayama H. Attachment systems for implant retained overdentures: a literature review. Implant Dent 2006;15:24-34.
Received January 17, 2018 Accepted July 10, 2018 